UDK 528.5

\title{
NEW MODEL OF THE VERTICAL CRUSTAL MOVEMENTS IN THE AREA OF POLAND
}

\author{
Kamil Kowalczyk \\ Dept of Surveying, University of Warmia and Mazury in Olsztyn, Jana Heweliusza 12, Olsztyn, Poland, \\ e-mail: kamil.kowalczyk@uwm.edu.pl \\ Received 0505 2006, accepted 17062006
}

\begin{abstract}
In 2003 the fourth levelling campaign has been finished in Poland. This campaign, together with the previous one carried out in 1974-1982, gave a very good opportunity to determine the land uplift in the area of Poland. The paper describes shortly the third and fourth campaigns, the computation of the relative land uplift, computation of land uplift referred to the mean sea level and modeling the land uplift by the least-squares collocation method. Obtained results are compared with the computation done by the Institute of Geodesy and Cartography in 1986.
\end{abstract}

Keywords: land uplift, mean see level.

\section{Introduction}

Analysis of contemporary vertical crustal movements and prediction of such movements has been the centre of interest for geodesic research groups for a long time. Those movements are caused by changes in the shape, size and position of the Earth as a planet. Elaboration of a model of those changes is one of the major tasks of deformations analysis. Currently, the vertical crustal movements may be identified on the basis of the levelling data, observations on permanent GPS stations, tide gauge and gravimetric observations.

The paper uses the data of the third and fourth precision levelling campaigns in Poland and the data from tide gauge stations in Władysławowo, Ustka, Kołobrzeg and Świnoujście. On the basis of those data a model of vertical movements in the area of Poland was developed. During the first stage of the study, the relative vertical crustal movements refered to the tide gauge in Władysławowo were computed. Next the vertical movements of tide gauge in Władysławowo in respect to the mean sea level of the Baltic Sea were determined. Elements of statistical analysis: moving average and linear regression methods were used for identification of tide gauge motions. Finally, the vertical movements of network bench marks relative to the mean sea level were determined. The model of vertical crustal movements in the area of Poland was developed by applying the interpolation method.

The model developed in that way should provide surveyors, geophysicists and geologists with precious information on the behaviour of earth crust in the area of Poland. The model should also allow development of a kinematical levelling network in Poland.

\section{Sources of vertical movements}

As it is known, vertical crustal movements are caused by geophysical processes as well as processes resulting from human activities [1].

Geophysical processes (Fig 1) are the crustal movements caused by external and internal factors such as formation and disappearance of continental glaciers, changes in the volume of water in reservoirs, sedimentation, erosion, increased load of the crust resulting from orogenetic movements and transformations of minerals occurring in the lithosphere as well as convection current in the Earth mantle.

Artificial processes (Fig 2) causing vertical crustal movements result from human activities such as mining of deposits, drainage or watering of the land and transportation as well as nuclear arms testing.

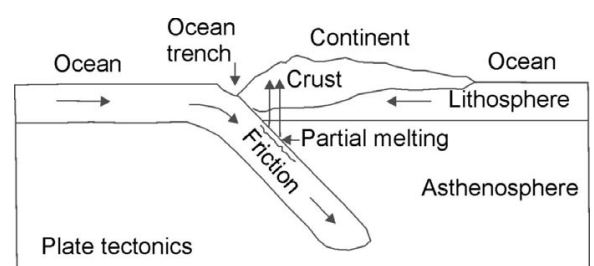

Fig 1. Example of geophysical processes causing vertical movements [2]

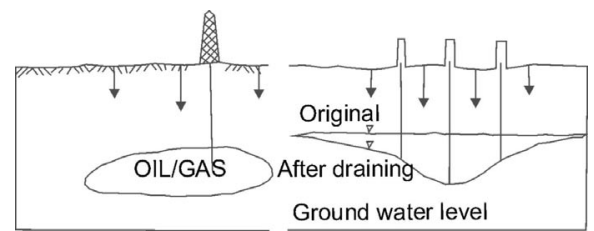

Fig 2. Example of artificial processes causing vertical movements [2] 


\section{Earlier determination of land uplift in Poland}

In 1960, J. Niewiarowski and T. Wyrzykowski [3] carried out the first determination of the vertical movements in the area of Poland. Those movements were calculated by levelling data from the years 1952-58 (I and II class) and 1926-37 (I class), by the very simple method. That method was based on height comparison of common points in two adjusted nets connected to the same point assumed as fixed [3].

The second determination of vertical crustal movements in the area of Poland was carried out during the years 1977-87. The calculations used the levelling measurements from the years 1947-60 and 1974-79 [4]. The map of vertical crustal movements presented in Fig 3 is the final result of those calculations.

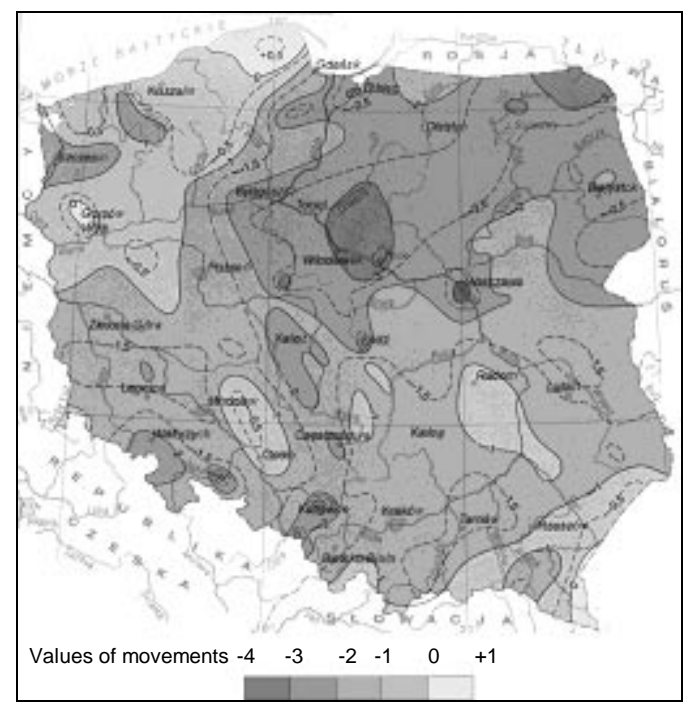

Fig 3. Land uplift in the area of Poland [4]

\section{Data used}

The computations presented in this paper used the levelling data, without ordinary adjustments, from the last two precise levelling campaigns.

Measurement of the network during the years 1974-82 (the third campaign) was carried out in two stages: 1974-79 and its densification during the years 1980-82. The levelling network was connected to 7 major Polish tide gauge stations. The observations were corrected due to staff calibration correction, staff thermal correction, correction for changes in the direction of the vertical line caused by the Moon and Sun (segments I and II). The overall length of the levelling lines was $17015 \mathrm{~km}$ while the average length of levelling section was $1,1 \mathrm{~km}$. The standard deviation computed from the residuals was $\pm 0,84 \mathrm{~mm}$.

The fourth levelling campaign during the years 1997-2003 covered the entire country. Measurement of the levelling network was carried mainly along the same levelling lines as in 1974-82 with minor changes. Fig 4 presents common nodal and pseudo-nodal points obtained from comparison of campaigns of 1974-79 and 19992003. As a result, 235 common points from the two campaigns were obtained.

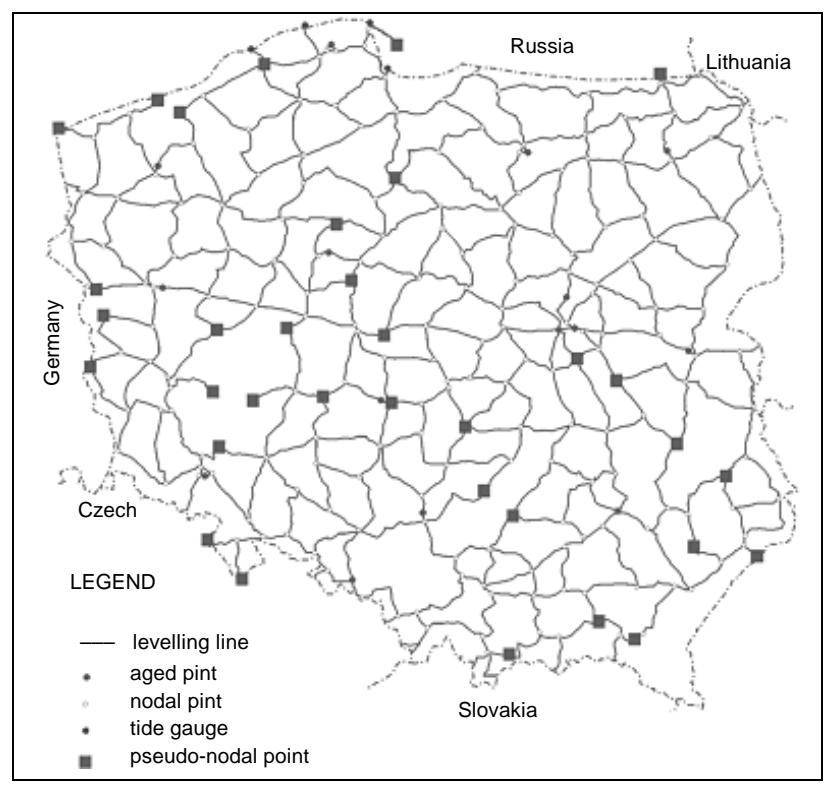

Fig 4. Common nodal points and pseudo-nodal points

\section{Determination of the land uplift from levelling data}

A method that has no overly restrictive requirements was chosen for the studies. The data from the first and the second campaign do not have to be measured in two equal time intervals. The relative vertical movements for each levelling line were computed from the formula [5]:

$$
\Delta v=\frac{\Delta h_{2}-\Delta h_{1}}{\Delta t},
$$

where $\Delta h_{1}$ and $\Delta h_{2}$ represent differences in height between the same bench marks from the first and the second campaign, while $\Delta t$ is the time interval between those two measurements.

Relative vertical movements of lines determined in that way were adjusted using the parametric method [6] by the FIXIT2 DOS/L software version of 29 July 1994.

The first adjustment stage covered preparation of the input file with names of all nodal points and numbers of the initial and terminal points of levelling lines. Values equal to zero were applied as horizontal coordinates for all nodal points. The adjustment was done in one stage assuming that the nodal point in Władysławowo is fixed. The values of weights adjusting of the variance factor. Obtaining as a result the value of that coefficient is equal to 1 . No gross errors in adjustment were found, which indicates that the data were prepared well. 


\section{Determination of mean sea level at tide gauge stations}

Along the Polish Baltic coast there is a number of tide gauge stations and mareographic data from those stations that can be obtained from the tide gauge database of the Permanent Service of Mean Sea Level (PSMSL).

The mean sea level was determined by four tide gauge stations (Fig 5) selected their location and continuity of mareographic data.

The data (49 for each selected station) represent mean year values of sea level reduced to the common reference level and analysed for quality by the PSMSL.

The selected stations have operated longer than the period covered by the study; however, only the data for the period when float tide gauge were in operation was used. In 2002 a permanent GPS receiver has been installed in Władysławowo as the only tide gauge station in Poland.

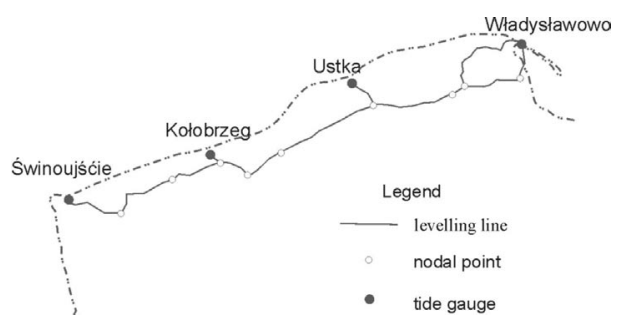

Fig 5. Selected tide gauge stations at Polish coastline

During the first stage the tide gauge data (year mean values) were subjected to smoothing using the moving average method.

The moving average projects the values during the projection period. It is based on the basis of the average value of the variable. This average value is calculated for the defined number of preceding periods. In that method, each element of the series is substituted by the weighted average of the neighbouring elements. The number of neighbouring elements is defined by the "window". The window size should be equal to the longest period present in the observation data. It suggests that the window should be around 20 years (18,9 years is the period for orbital period of Moon nodes) [7]. In case of a "rectangular" window all elements have identical weights.

An example of tide gauge data is given in Fig 6. These data are from Władysławowo tide gauge station. The upper figure presents the character of mean sea level changes before smoothing, while the lower one - after smoothing. As can be seen in the figure, the data smoothed by the moving average is of more uniform character.

During the second stage, the linear trend of mean Baltic Sea level was determined by the regression method. The literature indicates that linear regression is relatively simple and reflects well the real sea level changes. According to that method two parameters describing the changes are determined.

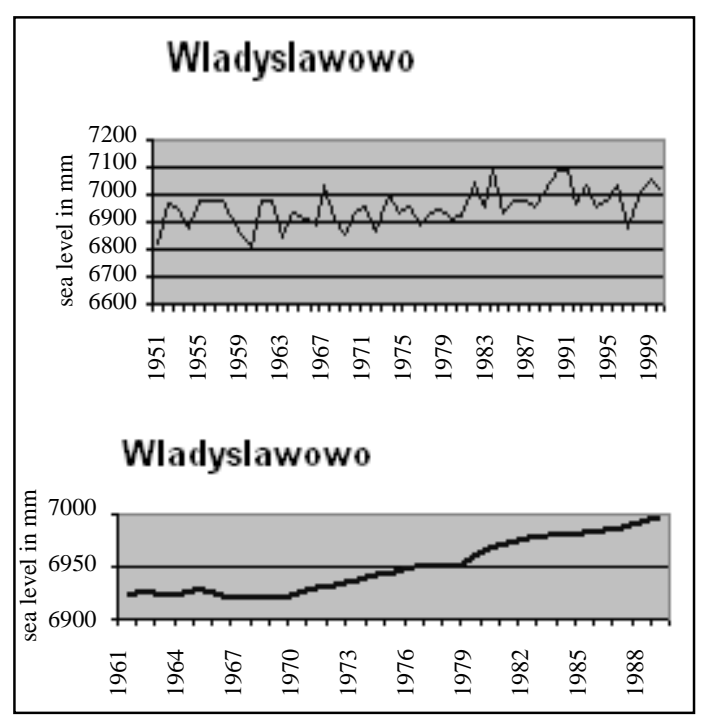

Fig 6. Tide gauge data before (up) and after smoothing (down)

One is the slope of line $b$ indicating the speed of changes and the initial value $a$ for those changes.

$$
\hat{y}_{i}=a+b x_{i} .
$$

The information on quality of the regression is provided by $R^{2}$ coefficient. The closer it is to one, the better the trend is adjusted to the data.

The obtained mean $R^{2}$ coefficient values are 0,9 . That is an almost perfect coefficient, so adjustment of the line regression to the data was done correctly. Table 1 presents the obtained results of linear regression computations for the data before and after smoothing with the moving average.

Table 1. Results obtained from linear regression computations on raw data and smoothed data

\begin{tabular}{l|l|c|c|c|c|}
\hline \multirow{2}{*}{ Station name } & \multicolumn{2}{c|}{$\begin{array}{c}\text { Linear trend } \\
\text { [mm/year] }\end{array}$} & \multicolumn{2}{c|}{$R^{2}$ coefficient value } \\
\cline { 2 - 5 } & Before & After & Before & After \\
\hline Władysławowo & 2,40 & 2,98 & 0,2527 & 0,9255 \\
\hline Ustka & 1,69 & 2,12 & 0,1695 & 0,9534 \\
\hline Kołobrzeg & 1,25 & 1,66 & 0,1143 & 0,8735 \\
\hline Świnoujście I & 0,86 & 0,88 & 0,5072 & 0,9098 \\
\hline Świnoujście II & 1,40 & 1,35 & 0,1523 & 0,9251 \\
\hline \\
$\begin{array}{l}\text { STATISTICA software was used for this } \\
\text { computations. }\end{array}$
\end{tabular}

\section{Vertical movements at the tide gauge stations in Poland}

There is a close correlation between sea level changes and the vertical movement of tide gauge stations. The vertical movement of a tide gauge station in respect to the mean sea level is the inverse of the sea level changes direction, if we assume stability of the station itself. 
Table 2 presents the vertical movements at tide gauge stations determined in this study. The obtained results were compared to the values given in $[4,8]$.

Table 2. Vertical movements at the tide gauge stations in Poland and their standard deviations

\begin{tabular}{|c|c|c|c|}
\hline Station name & $\begin{array}{c}v_{0} \mathrm{~mm} / \text { year } \\
{[4]}\end{array}$ & $\begin{array}{c}v_{0} \mathrm{~mm} / \text { year } \\
{[8]}\end{array}$ & $\begin{array}{c}v_{0} \mathrm{~mm} / \text { year } \\
\text { (estimated) }\end{array}$ \\
\hline Władysławowo & $-0,1$ & $-2,6$ & $-3,0$ \\
\hline Ustka & $+0,1$ & $-1,0$ & $-2,1$ \\
\hline Kołobrzeg & $-1,0$ & $-1,1$ & $-1,7$ \\
\hline Świnoujście & $-0,7$ & $-1,1$ & $-1,4$ \\
\hline
\end{tabular}

\section{Determination of the vertical land uplift relative} to the mean sea level

To determine the vertical crustal movements relative to the mean sea level it is necessary to connect the levelling network to the sea level. According to [9], the tide gauge station in Władysławowo is the tide gauge that satisfies the required criteria.

In this study the vertical movements at Władysławowo station were determined according to the methodology in section 6 .

The nodal point Władysławowo was connected to the tide gauge station and the value of movement on this nodal point equal to $-0,5 \mathrm{~mm} /$ year was obtained. The vertical movement at the mareographic station in Władysławowo was assumed to be $-2 \mathrm{~mm} /$ year.

There is a number of model development methods. The ultimate model of vertical movements will be developed by interpolation using the collocation method.

\section{Interpolation by the collocation method}

The collocation method proposed by Krrarup in the 1950s, spread by Moritz, found first of all a broad use in physical geodesy, but it can be successfully applied for other fields of geodesy, among others, for interpolation of vertical crustal movements. The theoretical bases of this method presented in this paper were developed on the information provided in $[10,11]$.

Markov's function and Hirvonen's function were analysed as the analytic function.

To determine the empirical covariance function on a representative group of points nodal bench marks of a network of vertical movements were assumed. The variance was given in $\mathrm{mm}^{2}$, the correlation distance in degrees of the arc.

The calculations yielded the following values of parameters of the empirical covariance function determined on the basis of nodal bench marks:

$$
\begin{array}{ll}
C_{0} \text { variance } & 0,2928 \\
1 / 2 C_{0} & 0,1464 \\
\text { correlation distance } & 0,3652
\end{array}
$$

The figure below presents a diagram of the empirical covariance function and diagrams of Markov's and Hirvonen's analytical functions.



Fig 7. Diagram of the empirical covariance function calculated on the basis of nodal bench marks

As shown in Fig 7, Hirvonen's analytical function is better matched to the empirical function. This is why it was decided to determine the model exactly with the use of this function.

\section{Model of vertical land uplift in the area of Poland}

The realisation of the interpolation required the preparation of appropriate data, on which calculations were performed. The intersections of meridians and parallels in the area of Poland were assumed as interpolated points in intervals of 20'x20' (Fig 8).



Fig 8. The grid of meridians and parallels $20^{\prime} \times 20^{\prime}$ against the background of Poland's borders and the double levelling network

To avoid the formation of a singular matrix, using Matlab's authoring scripts, an attempt was made to define the optimum area to base the determination of the vertical movement. On this basis and after several tests, the optimum area was defined by a $50 \mathrm{~km}$ radius.

The observed vertical movements at nodal bench marks were assumed as points of departure for interpolation with values determined in relation to the nodal benchmark in Władysławowo connected with the mareographic station in Władysławowo. The interpolation was performed with the use of own scripts written in the Matlab program.

These programs, named MARKO and HIRVONEN, serve for interpolation by the method of collocation with 
the use of appropriate covariance functions and calculating the interpolation mean error.

The model of the contemporary vertical crustal movements in the area of Poland (Fig 9) was created in two variants [12]: as a numerical set of interpolated vertical movements in points of the grid of meridians and parallels and an analog map of vertical crustal movements in the area of Poland.

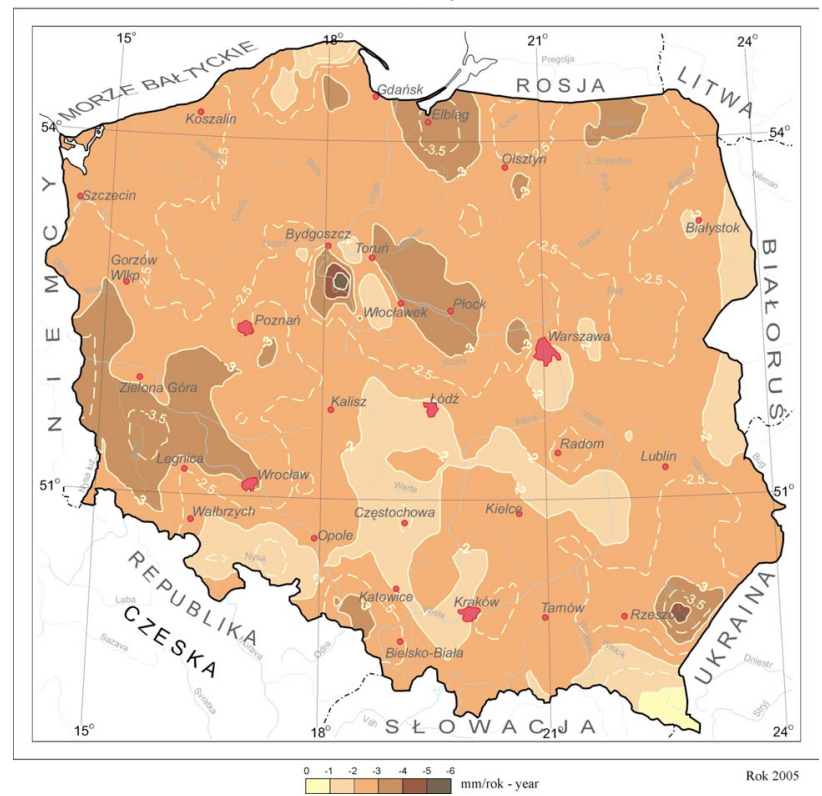

Fig 9. Model of vertical land uplift in the area of Poland, 2005

On the basis of the numerical model, the possibility exists of interpolating vertical movements anywhere in Poland. The first tests were carried out by Prof Adam Łyszkowicz.

\section{Conclusions}

- A model of the contemporary vertical movements of Earth's crust was developed for the area of Poland. For this purpose, levelling data was used from the years 1974-82 and 1997-2003. This model was referred to the mean level of the Baltic Sea's southern coast. It is developed as a numerical set of interpolated vertical movements in points of the grid of meridians and parallels and an analog map of vertical crustal movements in the area of Poland.

- No positive movements occur in Poland. The greatest negative vertical movements were found near Inowrocław and Rzeszów (below $-5 \mathrm{~mm} /$ year), both regions lie in the so-called T-T tectonic movements zone. Near Warsaw, vertical movements vary from $-1 \mathrm{~mm} /$ year to $-3 \mathrm{~mm} /$ year. In the major part of Poland area, movements range from $-1,5 \mathrm{~mm} /$ year to $-3 \mathrm{~mm} /$ year. Vertical movements above $-3 \mathrm{~mm} /$ year occur near Elblag (the Vistula Delta Plain), Płock, Toruń and Włocławek (border of the T-T zone) and in the area of western Poland: from Wrocław to Legnica through Zielona Góra to Gorzów Wielkopolski (this is an area of Variscides on the border with the Czech massif). The smallest negative movements were recorded in the areas of southern Bieszczady (the Carpathian Mountains).
- On the basis of data from the numerical set of vertical movements, the possibility exists to interpolate vertical crustal movements in the area of Poland in any point in the country.

- The first tests of the model indicate its correctness. However, the necessity exists of further verifying the developed model of vertical crustal movements in the area of Poland.

- This model can constitute, after testing, a valuable contribution to the kinematic development of the UELN network.

\section{References}

1. Vaniček, P.; Krakiwsky, E. Geodesy: the concepts. Chapter 26: Detection of vertical movements. North-Holland, 1982, p. 607-628.

2. Leonhard, Th.; Niemeier, W.; Pelzer, R. Determination of vertical crustal movements from different regional levellings concept of the computing centre. In: Workshop on Precise Levelling, March 16-18, Dummler Verlag, 1983, p. 451-465.

3. Niewiarowski, J.; Wyrzykowski, T. Determination of velocity of recent vertical movements of the earth crust on the territory of Poland by comparison of results of repeated precise levellings. In: Proceedings of the Institute of Geodesy and Cartography. Vol VII, No 1(17), 1961, p.102-109.

4. Wyrzykowski, T. A New determination of velocity of recent vertical movements of the earth crust on the territory of Poland. In: Proceedings of the Institute of Geodesy and Cartography, Vol XXXIV, No 1(78), 1987, p. 41-62.

5. Sandford, H.; Holdahl (in ed. I. Mueller). Models for extracting vertical crustal movements from levelling data. Reports of the Department of Geodetic Science, The Ohio State University, Report 280, 1978, p. 183-190.

6. Baran, L. W. Theoretical bases' elaborate of results geodetical measurements. PWN, 1999. 344 p.

7. Łyszkowicz, A. Report with realization researching task, Qualitative analysis and quantitative existing data tide gauge. Olsztyn, 2003. 34 p.

8. Łyszkowicz, A. Relative mean surface topography along the southern part of Baltic Sea. Artificial Satellites, Planetary Geodesy, No 25, 1995, p. 133-141.

9. Łyszkowicz, A.; Zieliński, J. B. State of the vertical datum in Poland as an Example From Eastern and Central Europe. In: Proceedings of the International Symposium on Marine Positioning INSMAP 1994, Hanover, 1994. Printed by PIP PRINTING USA, p. 261-271.

10. Heiskanen, W.; Moritz, H. Physical Geodesy. Heights Above Sea Level. W. H. Freeman and Company, San Francisco and London, 1967, p. 161-171.

11. Moritz, H. Advanced physical geodesy. H. Wichmann Verl., Karlsruhe, 1980. 512 p.

12. Kowalczyk, K. Model calculation of vertical movements of the earth's crust on area of Poland. Doctor's trial UW-M, Olsztyn, 2006. 112 p.

Kamil KOWALCZYK. Research \& education post, Dept of Surveying, Faculty of Geodesy and Land Management, University of Warmia and Mazury in Olsztyn, Jana Heweliusza 12, 10-900 Olsztyn, Poland,

e-mail: kamil.kowalczyk@uwm.edu.pl.

A graduate of University of Warmia and Mazury in Olsztyn, M.Sc. in 2001. Doctor engineer degree (advanced geodesy) in 2006. Schooling of subject: "Creating maps" and "Geodesy", author of school-book "Select problems in creating maps", author of many publications about Earth's crust vertical movements.

Research interests: vertical movements of the Earth's crust, GPS, RTK, maps and data bases. 